\title{
Community resilience monitoring and evaluation under the prevention and control of public health emergencies
}

\author{
Shuang Liu, ${ }^{1, *}$, Yixi Wang 2 , Zixiao $\mathrm{Li}^{3}$, Dandan Zhang ${ }^{4}$, Kuntai $\mathrm{Yu}^{5}$ \\ ${ }^{1}$ Department of Assets Appraisal, Sichuan Agricultural University, Chengdu, China \\ ${ }^{2}$ Department of Assets Appraisal, Sichuan Agricultural University, Chengdu, China \\ ${ }^{3}$ Department of Assets Appraisal, Sichuan Agricultural University, Chengdu, China \\ ${ }^{4}$ Department of Accounting, Sichuan Agricultural University, Chengdu, China \\ ${ }^{5}$ Department of Accounting, Sichuan Agricultural University, Chengdu, China
}

\begin{abstract}
In order to monitor the level of community resilience and the quality of the living environment under public health emergencies, 13 communities in Xingfu Street, Dujiangyan City are taken as the empirical research objects, and the PSR model-entropy method is used to construct a community-based public health emergency prevention and control resilience assessment model to explore the existing problems of the community's epidemic prevention capabilities and the quality of the human settlement environment. The results show that: (1)The resilience level and the quality of the living environment of the series of communities under Xingfu Street are generally average, and there are big differences in resilience between communities. (2) In the construction indicators, "Total per capita income loss" and "Proportion of population over 65" have significant negative impact, "Application level of new prevention and control technology", "Number of community medical staff", "Proportion of medical staff with intermediate and above titles", " Exchangeability and sharing of health information resources" and "Number of hospital beds" have significant positive impact. (3) The resilience of the prevention and control of public health emergencies in the community is most significantly affected by medical resources, but the community medical resources are generally scarce and the development is not coordinated. Xingfu Street series communities should focus on improving the level of basic medical services, promote resilience building in stages, and realize the organic combination of dynamic epidemic prevention and sustainable development.
\end{abstract}

\section{Preface}

Community resilience is the ability and process of the community system to buffer and respond to the impact of uncertainties such as natural disasters, and realize the normal operation of public safety, social order, and economic construction ${ }^{[1]}$. The outbreak of the new crown epidemic in 2020 has made community resilience under public health emergencies a hot spot of concern. In the process of fighting the epidemic, the community has played the role of coordinating the smooth operation of the grassroots society, organizing disinfection and isolation, and the grid model for scientific and efficient anti-epidemic functions. It is an important line of defense for the grass-roots anti-epidemic. However, in the process of fighting the epidemic, it has also been exposed that the community still has problems in the response to public health security incidents, such as lack of plans, insufficient material reserves, low level of informatization, low efficiency in the application of new technologies, and excessive prevention and control ${ }^{[2]}$. The community is the basic unit of social governance, and great attention should be paid to the role of the community as a basic platform for responding to public health emergencies ${ }^{[3]}$. In the face of the normalization of the epidemic, systematically improving the resilience of the human settlement environment and human society in the face of sudden changes and disturbances are issues that we urgently need to think about. Improving community resilience is the key to solving this problem.

In the context of the frequent occurrence of global disasters, the current community resilience research perspective mainly focuses on disasters and uncertainty disturbances ${ }^{[4]}$. Scholars such as Yang Wei (2015), Jiang Yuxiao (2017), and Fang Dongping (2020) have conducted research and discussion on community resilience from the perspective of emergency management, rain and flood prevention, and earthquake prevention and control ${ }^{[5-7]}$. But on the whole, scholars mainly construct a community resilience evaluation system from the perspectives of natural disasters, accidents, and social security incidents. They lack a community resilience evaluation system specifically for the prevention and control of public health emergencies, and there is a lack of relevant indicator system empirical research. How to rationally and scientifically select 
community resilience evaluation indicators from the perspective of emergency public health prevention and control, and empirical evaluation of community resilience to epidemic prevention still needs further discussion.

Based on the above background, this study takes 13 communities in Xingfu street, Dujiangyan City as the empirical research objects, starting from the prevention and control of public health emergencies, comprehensively uses the PSR model-entropy method to build the community resilience evaluation index system, evaluates the resilience level of the community in the prevention and control of public health emergencies, and finds out the key problems of the community in coping with public health emergencies Then, the feasible path and policy suggestions to optimize the resilience of community and improve the quality of community living environment are put forward.

\section{Overview of research area}

Xingfu Street of Dujiangyan City is located in the core area of Dujiangyan City, China. It is composed of 13 communities including Xingfu Community, Rainbow Community, Xiangfengqiao Community, Minjiang Road Community, Guanfenglou Community, Jiefang Community, Lianhua Community, Yongfeng Community, You'ai Community, Alliance Community, Xinlian Community, Shima Community and Yongshou Community. Among them, Shima Community and Yongshou Community are located in the urban-rural combination area, and the rest are located in the main urban area.The traffic in this area is convenient, and it is close to Dujiangyan Center for Disease Control and Prevention, Dujiangyan Bureau of Statistics, Dujiangyan People's Court and Dujiangyan Municipal Government. There are 150 residential groups,448 courtyards and 1357 enterprises, including 163 non-public enterprises and 6990 individual industrial and commercial households. By the end of 2019, the financial income of Xingfu Street was 32.88335 million yuan, and the per capita disposable income of urban and rural residents was 37340 yuan, slightly higher than the national average level (30733 yuan).

There are 78 grid inspectors in Xingfu Street, the overall level of public security is high, the economic condition and social security condition are good. There are 3 health service centers including Xingfu Street Health Service Center, Jiefang Community Health Service Center, Guihua Health Service Center,14 community health service stations, 3 village health stations, equipped with public fire equipment, fire stairs, fire passage, elevator and other infrastructure. In the new epidemic situation in 2020, Xingfu Street makes contribution to the anti-epidemic work and actively recruits volunteers to jointly resist the epidemic situation through the linkage of organization, party and masses and the linkage of the whole people. In addition, by carrying out epidemic prevention education and strictly controlling the external personnel and other epidemic prevention measures, the communities under the street have realized the " 0 " infection of the COVID-19 virus.

\section{Data and research methods}

\subsection{Data Sources}

The data based on which the indicators are established in this paper are from the Chinese government website, Chengdu grassroots open comprehensive service supervision platform, Chengdu public enterprises and institutions open platform, Chengdu Health Committee official website, Chengdu Statistics Bureau official website, Xingfu Street Office official website, Xingfu Street subordinate community official website and other government websites, enterprise search official website, residents' website Questionnaire survey data and interview records of community party and mass service center and community hospital.

\subsection{General thoughts of research}

This study takes Dujiangyan Xingfu Street as an example. Firstly, using the PSR model and the thinking logic of "cause-effect-response" to break down the whole process of community system dealing with the disturbance of public health emergencies, to identify the influencing factors in the field of "pressure-state-response" of community resistance to epidemic, and to construct the evaluation index system of community public health emergency prevention and control resilience; secondly, using the entropy method to determine the index weight, and to calculate the levels of "community resilience "," pressure resilience "," state resilience" and "response resilience" accordingly; finally, according to the evaluation results of resilience, analyze and study the toughness characteristics of regional samples, and divide the toughness grades.

\subsection{Constructing Index System}

PSR refers to pressure, state and response. PSR model is used to analyze the relationship between environmental pressure, current situation and response. From the perspective of prevention and control of public health emergencies, this study draws on the idea of PSR model and defines "stress" as: the adverse impact of public health emergencies on the community and the possibility of harm; defines "state" as: the state level of medical resources, society and economy when the community system is resisting public health emergencies; and defines "response" as the ability of community to recover from public health emergencies to the normal operation level and the ability of learning and adapting.

Starting from the prevention and control of public health emergencies, using the "PSR model ", it is found that the influential factors of" stress resilience "are public health emergencies, the influential factors of" state resilience "are medical resources, social conditions and economic conditions, and the influential factors of" response resilience "are early warning ability, recovery ability and learning adaptability ability. On the basis of the characteristics of each field,28 indexes such as "Infection rate "," Distance from the nearest high-risk 
area" and " Epidemic awareness" were selected as the specific evaluation indexes. Finally, a community resilience evaluation index system under the perspective of prevention and control of public health emergencies is established (see Table1 for specific indexes).

\subsection{Determination of index weights at all levels}

\subsubsection{Measure Method Selection - Entropy Method}

After constructing the evaluation index system with the above indexes, collect the data of each index of the research object (Xingfu Street Community), and finally determine the index weight by entropy method. Under the entropy method, when the dispersion degree of an index is greater, it indicates that the effective information provided by the series is greater, the smaller the entropy value is, the greater the influence of the index on the comprehensive evaluation is, and the higher the weight value is; otherwise, the smaller the dispersion degree is, the greater the entropy value is, the lower the weight value is; when the data of an index is identical, the invalid information is, and the weight value is zero, which can be eliminated from the evaluation system.

\subsubsection{Construction of original matrix}

The matrix of 23 (community sample)*28(index) was constructed. The value of item $j$ of community $i$ is $x y_{i j}$.

\subsubsection{Data Standardization Processing}

Because the unit of measurement of each index in the index system is not uniform, and the positive index and the negative index are included at the same time (the higher the positive index is, the lower the negative index is), it is necessary to standardize the data, that is, to convert the absolute value of the index into the relative value, and to homogenize the non-homogeneous index. The specific methods are as follows:

Positive indicators:

$$
x_{i j}^{\prime}=\frac{x_{i j}-\min \left\{x_{1 i}, \cdots, x_{n i}\right\}}{\max \left\{x_{1 i}, \cdots, x_{n i}\right\}-\min \left\{x_{1 i}, \cdots, x_{n i}\right\}}
$$

Negative indicators:

$$
x_{i j}^{\prime}=\frac{\max \left\{x_{1 i}, \cdots, x_{n i}\right\}-x_{i j}}{\max \left\{x_{1 i}, \cdots, x_{n i}\right\}-\min \left\{x_{1 i}, \cdots, x_{n i}\right\}}
$$

\subsubsection{Calculating the entropy value of the $j$ th index}

$$
\begin{gathered}
P_{i j}=\frac{x_{i j}^{\prime}}{\sum_{i=1}^{n} x_{i j}^{\prime}},(i=1,2 \ldots, n ; j=1,2 \ldots, m) \\
e_{j}=-k \sum_{i=0}^{n} p_{i j} \ln \left(p_{i j}\right),(i=1,2 \ldots, n ; j=1,2 \ldots, m) \\
k=1 / \ln (n)
\end{gathered}
$$

\subsubsection{Calculation of entropy redundancy}

$$
\begin{aligned}
& d_{j}=1-e_{j},(j=1,2 \ldots, m) \\
& W_{j}=\frac{d j}{\sum_{j=1}^{m} d_{j}},(j=1,2 \ldots, m)
\end{aligned}
$$

\begin{tabular}{|c|c|c|c|c|}
\hline Process & Domain level & Index layer & Attribute & Relative weight \\
\hline \multirow{4}{*}{$\begin{array}{l}\text { Pressure } \\
\text { (B1) }\end{array}$} & \multirow{4}{*}{$\begin{array}{l}\text { Public health } \\
\text { emergencies } \\
\text { (C1) }\end{array}$} & (C11) Infection rate $(\%)$ & $\begin{array}{l}\text { Negative } \\
\text { Direction }\end{array}$ & $0.00 \%$ \\
\hline & & (C12) Distance from the nearest high-risk area $(\mathrm{km})$ & Forward & $2.11 \%$ \\
\hline & & (C13) Epidemic awareness (5 points) & Forward & $2.71 \%$ \\
\hline & & (C14) Total per capita income loss (RMB) & $\begin{array}{l}\text { Negative } \\
\text { Direction }\end{array}$ & $2.80 \%$ \\
\hline \multirow{12}{*}{$\begin{array}{l}\text { State } \\
(\mathrm{B} 2)\end{array}$} & \multirow{4}{*}{$\begin{array}{l}\text { Status of } \\
\text { medical } \\
\text { resources } \\
\text { (C2) }\end{array}$} & (C21) Number of community medical staff(person) & Forward & $8.62 \%$ \\
\hline & & $\begin{array}{l}\text { (C22) Proportion of medical staff with intermediate and above } \\
\text { titles }(\%)\end{array}$ & Forward & $5.13 \%$ \\
\hline & & $\begin{array}{l}\text { (C23) Exchangeability and sharing of health information } \\
\text { resources ( } 5 \text { points) }\end{array}$ & Forward & $3.83 \%$ \\
\hline & & (C24) Number of hospital beds & Forward & $8.72 \%$ \\
\hline & \multirow{5}{*}{$\begin{array}{l}\text { Society } \\
\text { State } \\
\text { (C3) }\end{array}$} & (C31) Community public security level(5 points) & Forward & $2.51 \%$ \\
\hline & & (C32) Community floating population (\%) & $\begin{array}{l}\text { Negative } \\
\text { Direction }\end{array}$ & $3.46 \%$ \\
\hline & & (C33) Population density (person $/ \mathrm{km}^{2}$ ) & $\begin{array}{l}\text { Negative } \\
\text { Direction }\end{array}$ & $6.29 \%$ \\
\hline & & (C34) Infrastructure allocation level(5 points) & Forward & $2.94 \%$ \\
\hline & & (C35) Proportion of population over 65 years old (\%) & $\begin{array}{l}\text { Negative } \\
\text { Direction }\end{array}$ & $3.70 \%$ \\
\hline & \multirow{3}{*}{$\begin{array}{l}\text { Economy } \\
\text { State } \\
\text { (C4) }\end{array}$} & (C41) Per capita disposable income (yuan/person) & Forward & $2.30 \%$ \\
\hline & & (C42) Commercial development level(5 points) & Forward & $3.39 \%$ \\
\hline & & (C43) Proportion of tertiary industry $(\%)$ & Forward & $1.74 \%$ \\
\hline
\end{tabular}

Finally, using the data of 13 communities in Xingfu Street, we can calculate the index weight of Xingfu Street community resilience (Table 1).

Table1. Index and weight of toughness evaluation in Xingfu Street 


\begin{tabular}{|c|c|c|c|c|}
\hline \multirow{12}{*}{$\begin{array}{l}\text { Response } \\
\text { (B3) }\end{array}$} & \multirow{4}{*}{$\begin{array}{c}\text { Early warning } \\
\text { Ability } \\
\text { (C5) }\end{array}$} & (C51) Effective rate of emergency plan (five points) & Forward & $2.37 \%$ \\
\hline & & $\begin{array}{l}\text { (C52) Daily update frequency of epidemic prevention } \\
\text { information (times/day) }\end{array}$ & Forward & $3.54 \%$ \\
\hline & & (C53) Number of grid members(person) & Forward & $2.12 \%$ \\
\hline & & (C54) Quantity of monitoring tools & Forward & $2.66 \%$ \\
\hline & \multirow{4}{*}{$\begin{array}{c}\text { Recovery } \\
\text { capacity (C6) }\end{array}$} & $\begin{array}{l}\text { (C61) Proportion of annual community health expenditure in } \\
\text { total annual expenditure }(\%)\end{array}$ & Forward & $3.16 \%$ \\
\hline & & (C62) Harmless treatment rate of medical waste (\%) & Forward & $4.75 \%$ \\
\hline & & (C63) Community rehabilitation rate $(\%)$ & Forward & $2.75 \%$ \\
\hline & & (C64) Public participation (5 points) & Forward & $3.26 \%$ \\
\hline & \multirow{4}{*}{$\begin{array}{c}\text { Learning } \\
\text { Adaptability } \\
\text { (C7) }\end{array}$} & $\begin{array}{l}\text { (C71) Per capita number of emergency education and training } \\
\text { (times/person) }\end{array}$ & Forward & $2.91 \%$ \\
\hline & & $\begin{array}{l}\text { (C72) Effectiveness of prevention and control measures }(5 \\
\text { points) }\end{array}$ & Forward & $3.53 \%$ \\
\hline & & (C73) The prevalence of emergency skills increased(\%) & Forward & $4.87 \%$ \\
\hline & & $\begin{array}{l}\text { (C74) Application level of new prevention and control } \\
\text { technology( } 5 \text { points) }\end{array}$ & Forward & $3.85 \%$ \\
\hline
\end{tabular}

Notes:(1)Because the proportion of infected people in all communities of Xingfu street is 0 , that is, the weight of this index is 0 relative to the toughness assessment of each community of Xingfu street. Under the entropy method, the index of "Infection rate (\%)" should be deleted.(2)The index of "5 points" is calculated by five-point system.

\subsection{Calculation of toughness level}

The pressure toughness is $Q_{P}$, the state toughness is $Q_{S}$, the response toughness is $Q_{R}$ and the comprehensive toughness level is $Q$. There are:

$$
\begin{gathered}
Q_{P}=\sum_{j=1}^{4} W_{j} p_{i j},(i=1,2 \ldots, n) \\
Q_{S}=\sum_{j=5}^{12} W_{j} p_{i j},(i=1,2 \ldots, n) \\
Q_{R}=\sum_{j=13}^{28} W_{j} p_{i j},(i=1,2 \ldots, n) \\
Q=Q_{P}+Q_{S}+Q_{R}
\end{gathered}
$$

\section{Result Analysis}

Table2. Overall results and ranking of community resilience assessment in Xingfu Street

\begin{tabular}{|c|c|c|c|c|c|c|c|c|}
\hline $\begin{array}{c}\text { Community } \\
\text { Scores }\end{array}$ & $\begin{array}{c}\text { Pressure } \\
\text { system }\end{array}$ & $\begin{array}{c}\text { Stress } \\
\text { Ranking }\end{array}$ & State system & $\begin{array}{c}\text { State } \\
\text { Ranking }\end{array}$ & $\begin{array}{c}\text { Response } \\
\text { System }\end{array}$ & $\begin{array}{c}\text { Response } \\
\text { Ranking }\end{array}$ & $\begin{array}{c}\text { Comprehensive } \\
\text { toughness }\end{array}$ & $\begin{array}{c}\text { Comprehensive } \\
\text { ranking }\end{array}$ \\
\hline $\begin{array}{c}\text { Yongfeng } \\
\text { Community }\end{array}$ & 0.0369 & 12 & 0.1743 & 8 & 0.1499 & 11 & 0.3611 & 11 \\
\hline $\begin{array}{c}\text { Lianhua } \\
\text { Community }\end{array}$ & 0.0373 & 10 & 0.3994 & 2 & 0.1608 & 9 & 0.5975 & 4 \\
\hline $\begin{array}{c}\text { Guanfenglou } \\
\text { Community }\end{array}$ & 0.0305 & 13 & 0.367 & 3 & 0.1524 & 10 & 0.55 & 7 \\
\hline $\begin{array}{c}\text { Friendship } \\
\text { Community }\end{array}$ & 0.0425 & 4 & 0.1646 & 9 & 0.2518 & 3 & 0.459 & 8 \\
\hline $\begin{array}{c}\text { Xiangfengqiao } \\
\text { Community }\end{array}$ & 0.0401 & 7 & 0.3452 & 5 & 0.1766 & 8 & 0.5619 & 5 \\
\hline $\begin{array}{c}\text { Alliance } \\
\text { Community }\end{array}$ & 0.0529 & 2 & 0.1559 & 10 & 0.2311 & 4 & 0.4399 & 9 \\
\hline $\begin{array}{c}\text { Xingfu } \\
\text { Community }\end{array}$ & 0.0396 & 9 & 0.5067 & 1 & 0.1986 & 6 & 0.7449 & 1 \\
\hline $\begin{array}{c}\text { Xinlian } \\
\text { Community }\end{array}$ & 0.0706 & 1 & 0.1449 & 11 & 0.1968 & 7 & 0.4123 & 10 \\
\hline $\begin{array}{c}\text { Rainbow } \\
\text { Community }\end{array}$ & 0.0491 & 3 & 0.3233 & 6 & 0.2288 & 5 & 0.6012 & 3 \\
\hline $\begin{array}{c}\text { Minjiang Road } \\
\text { Community }\end{array}$ & 0.037 & 11 & 0.3652 & 4 & 0.2645 & 2 & 0.6667 & 2 \\
\hline $\begin{array}{c}\text { Jiefang } \\
\text { Community }\end{array}$ & 0.0401 & 7 & 0.1866 & 7 & 0.3243 & 1 & 0.5511 & 6 \\
\hline $\begin{array}{c}\text { Shima } \\
\text { Community }\end{array}$ & 0.0408 & 6 & 0.1147 & 12 & 0.0309 & 13 & 0.1864 & 13 \\
\hline $\begin{array}{c}\text { Yongshou } \\
\text { Community }\end{array}$ & 0.0421 & 5 & 0.0976 & 13 & 0.0511 & 12 & 0.1908 & 6 \\
\hline
\end{tabular}




\subsection{Pressure System Analysis}

The pressure resilience of the communities in the Xingfu Street series is evenly distributed, and they are less exposed to the impact of public health emergencies. The impact is mainly manifested in the loss of per capita income. The main reasons for this are the following four aspects: First, they are far from the recent high-risk areas of the epidemic, and the longer spatial distance reduces the pressure on prevention and control of communities; second, whether it is a community autonomous organization or community residents, all have a relatively complete understanding of the epidemic and attach great importance to epidemic prevention and control; third, although community residents are under economic pressure during public health emergencies, their total per capita income loss is relatively small compared to other regions; fourth, The number of people infected with the COVID-19 virus in the community is still zero so far, reducing the pressure of virus infection.

Among the 13 sample communities selected, Xinlian's community stress system score was the highest, with a stress system score of 0.0706 , because its per capita income was less affected by public health emergencies, and the community's overall awareness of the epidemic was also higher. For the sake of improvement, Xinlian community is the least under the pressure of public health emergencies in the Xingfu Street community. The Guanfenglou community has the lowest pressure score, as low as 0.0305 , because its residents' income loss is relatively large and the community's overall awareness of the epidemic is relatively imperfect. The stress system scores of the remaining communities fluctuated between 0.0529-0.0369.

\subsection{State System Analysis}

Overall, the scores of the community status system of the Xingfu Street series are relatively high. The main reasons are the following three aspects: first, the community's population mobility is weak, which reduces the possibility of virus transmission; second, the tertiary industry generally has a relatively high proportion and has high economic efficiency and vitality; third, The community's level of public security is higher, which better guarantees the prevention and control of the epidemic.

However, the status system scores of each community vary greatly, and the "status" system score fluctuates between 0.5067-0.0976, indicating that the level of state resilience among communities is uneven. The reasons are mainly manifested in the following two aspects: First, the uneven distribution of medical resources between the Xingfu Street series of communities is manifested in the number of medical staff in community health service stations, the proportion of medical staff with intermediate and above professional titles, and the exchange of health information resources. The gap in sharing is obvious; secondly, the distribution of infrastructure is uneven, among which the happy community is the most complete infrastructure, and the Shima community is the least equipped with the infrastructure.

\subsection{Response System Analysis}

The scores of the community response system of the Xingfu Street series are relatively concentrated, indicating that the 13 sample communities selected have similar levels of response resilience. The main reasons are the following three aspects: first, the number of grid members in each community is relatively even, and the efficiency of emergency plans is relatively similar; second, the proportion of annual community health expenditure in total expenditure, public participation and community return to work rate are similar; third, the prevention and control measures in each community are relatively effective, and the level of application of new prevention and control technologies is comparable.

Among the 13 sample communities selected, the Jiefang Community had the highest response system score, as high as 0.3243 . The per capita number of emergency education and training in this community and the increase in the penetration rate of emergency skills after the incident are ahead of other communities. The response system score of Shima community is the lowest at 0.0309 . This community is lower than other communities in terms of the harmless treatment rate of medical waste and the daily update frequency of epidemic prevention information. The scores of the rest of the community response system fluctuated between 0.2645-0.0511.

\subsection{Community resilience analysis}

Table3. Resilience level standards for prevention and control of public health emergencies in community

\begin{tabular}{|c|c|c|}
\hline $\begin{array}{c}\text { Toughness } \\
\text { grade }\end{array}$ & $\begin{array}{c}\text { Comprehensive } \\
\text { toughness score }\end{array}$ & $\begin{array}{c}\text { Toughness } \\
\text { Description }\end{array}$ \\
\hline $\mathrm{A}$ & $\mathrm{X}>0.6$ & Excellent \\
\hline $\mathrm{B}$ & $0.4<\mathrm{X}<0.6$ & General \\
\hline $\mathrm{C}$ & $\mathrm{X}<0.4$ & Poor \\
\hline
\end{tabular}

Table4. Comprehensive toughness assessment results of Xingfu Street

\begin{tabular}{|c|c|c|c|}
\hline $\begin{array}{c}\text { Community } \\
\text { Scores }\end{array}$ & $\begin{array}{c}\text { Comprehensiv } \\
\text { e toughness }\end{array}$ & $\begin{array}{c}\text { Toughness } \\
\text { grade }\end{array}$ & $\begin{array}{c}\text { Toughness } \\
\text { Description }\end{array}$ \\
\hline $\begin{array}{c}\text { Xingfu } \\
\text { Community }\end{array}$ & 0.7449 & $\mathrm{~A}$ & Excellent \\
\hline $\begin{array}{c}\text { Minjiang Road } \\
\text { Community }\end{array}$ & 0.6667 & $\mathrm{~A}$ & Excellent \\
\hline $\begin{array}{c}\text { Rainbow } \\
\text { Community }\end{array}$ & 0.6012 & $\mathrm{~A}$ & Excellent \\
\hline $\begin{array}{c}\text { Lianhua } \\
\text { Community }\end{array}$ & 0.5975 & $\mathrm{~B}$ & General \\
\hline $\begin{array}{c}\text { Xiangfengqiao } \\
\text { Community }\end{array}$ & 0.5619 & $\mathrm{~B}$ & General \\
\hline $\begin{array}{c}\text { Jiefang } \\
\text { Community }\end{array}$ & 0.5511 & $\mathrm{~B}$ & General \\
\hline
\end{tabular}




\begin{tabular}{|c|c|c|c|}
\hline $\begin{array}{c}\text { Guanfenglou } \\
\text { Community }\end{array}$ & 0.5500 & $\mathrm{~B}$ & General \\
\hline $\begin{array}{c}\text { Friendship } \\
\text { Community }\end{array}$ & 0.4590 & $\mathrm{~B}$ & General \\
\hline $\begin{array}{c}\text { Alliance } \\
\text { Community }\end{array}$ & 0.4399 & $\mathrm{~B}$ & General \\
\hline $\begin{array}{c}\text { Xinlian } \\
\text { Community }\end{array}$ & 0.4123 & $\mathrm{~B}$ & General \\
\hline $\begin{array}{c}\text { Yongfeng } \\
\text { Community }\end{array}$ & 0.3611 & $\mathrm{C}$ & Poor \\
\hline $\begin{array}{c}\text { Yongshou } \\
\text { Community }\end{array}$ & 0.1908 & $\mathrm{C}$ & Poor \\
\hline $\begin{array}{c}\text { Shima } \\
\text { Community }\end{array}$ & 0.1864 & $\mathrm{C}$ & Poor \\
\hline
\end{tabular}

According to the characteristics of the analysis results, the comprehensive tenacity of Xingfu Street community has obvious hierarchy (Table 4).According to the standard of community resilience in the prevention and control of public health emergencies, the comprehensive resilience scores of Xingfu Community, Minjiang Road Community and Caihong Community are all higher than 0.6, which classified as Grade A resilient community, Lianhua Community, Xiangfengqiao Community, Jiefang Community, Guanfenglou Community, You'ai Community, Alliance Community and Xinlian Community are higher than 0.4 and lower than 0.6 , which are classified as Grade B resilient community, Yongfeng Community, Yongshou Community and Shima Community are lower than 0.4 , which were classified as Grade $\mathrm{C}$ resilient community.

In the A and B level resilient communities, they are all located in the main urban area, and the community medical resources are relatively sufficient; the setting of community organizations is relatively reasonable and comprehensive; the community management system, autonomous system and emergency system are relatively perfect; the community people have a strong sense of belonging and emergency skills. On the contrary, most of the C-class communities are located in the urban-rural areas, which are lack of community development and have low resilience in public health emergencies.

\section{Conclusion and Discussion}

\subsection{Conclusion}

Based on the PSR model, this article constructs an evaluation index system of community resilience from the perspective of public health emergency prevention and control, uses entropy weight method to determine the index weight, and comprehensively evaluates the resilience of public health emergency prevention and control in 13 sample communities of Xingfu street in Dujiangyan City in 2020.The conclusions are as follows:

(1) The resilience level and the quality of the living environment of the Xingfu Street series of communities are generally average, and there are large differences in resilience between communities. In state resilience, medical resources can basically meet the daily medical needs of community residents, but there are problems such as uneven distribution of medical resources among communities and serious aging of the population; in response to resilience, community response capabilities basically meet the needs of community prevention, control and development, but There are deficiencies in the level of application of new prevention and control technologies. At the same time, from the comprehensive data, there are large differences in the resilience of communities, and the development of communities is not balanced. The resilience level of communities in the main urban areas is generally higher than that of communities in the urban-rural fringe area.

(2) The resilience of the Xingfu Street series of communities is mainly affected by seven indicators. Among the 28 indicators, "Total per capita income loss" and "Proportion of population over 65" have significant negative impact, "Application level of new prevention and control technology", "Number of community medical staff", "Proportion of medical staff with intermediate and above titles", " Exchangeability and sharing of health information resources" and "Number of hospital beds" have significant positive impact.

(3) The resilience of the prevention and control of public health emergencies in the community is most significantly affected by medical resources, but the overall lack of community medical resources and uncoordinated development. The number of medical staff with intermediate titles and above in the community accounts for a relatively small number, and every community hospital is in a state of carrying load when faced with a sudden epidemic. At the same time, the overall construction of the online consultation platform lags behind and needs to be further improved or developed. Second, the development of medical resources among communities is not coordinated. The number of medical staff in various communities and the number of beds in hospitals are uneven. Among them, the allocation of family physicians and family nurses is seriously unbalanced, and most communities are under-allocated.

\subsection{Discussion}

In response to the above conclusions, this study puts forward the following recommendations for the prevention and control of public health emergencies in Xingfu Street serial communities:

(1) Focus on improving the level of community basic medical services and enhancing the resilience of community medical resources. First of all, the community itself should set up health stations and other institutions according to the population ratio, balance the allocation of medical resources, learn and introduce advanced medical technology, and take the initiative to supplement the shortcomings of basic medical services. Secondly, the health system needs to strengthen the construction of community medical care, increase capital, talent, and technology investment, establish and improve a special family medical service mechanism, further promote the integration of online and offline medical resources, and focus on helping community hospitals located in urban and rural areas. Finally, the government needs to give policy preference to community medical and health undertakings, increase expenditures for the community in 
the medical and health sector, strictly implement the annual budget report, reduce the gap between budget and final accounts, and implement the work.

(2) Build a benign mechanism for mutual assistance and sharing among neighboring communities to enhance the social and economic resilience of communities. First of all, in community prevention and control, communities in adjacent areas can supervise each other, learn from each other, and increase the sharing of volunteer resources and epidemic prevention information among communities. Secondly, improve the configuration of infrastructure, pay attention to the current living conditions of the elderly and other special groups under the epidemic, and improve their standard of living security. At the same time, speed up the construction of smart communities, make the use of various funds and policies in the community more transparent, and increase the participation of community residents in community construction. Finally, strengthen the introduction of talents and industries to diversify the development of community industries and solve the problem of single industry development.

(3) Promote the building of resilience in stages and improve the dynamic prevention and control mechanism. The situation of public health emergencies is constantly evolving, and has obvious characteristics in each stage. According to the different stages of the development of the epidemic, the community needs to implement targeted measures to enhance community resilience, timely follow up prevention and control technology, make full use of emerging technologies such as big data and artificial intelligence, and adopt UAV monitoring, big data analysis, and online platform construction to help community resilience construction.

In summary, based on the perspective of public health emergencies prevention and control, this study uses PSR model entropy method to evaluate the resilience of prevention and control of public health emergencies of Xingfu Street series communities in 2020, and makes some innovation and supplement to the research perspective and ideas of community resilience. In addition, the unfinished points can still be discussed: the research on the prevention and control of public health emergencies is a long-term task. This research only uses the data of one year in 2020, but with the passage of time and more epidemic prevention features appearing in the future, we can establish a database for several consecutive years and do long-term longitudinal research to pay attention to the dynamic changes of community resilience in the prevention and control of public health emergencies.

\section{Acknowledgments}

This article is one of the phased results of the Sichuan Agricultural University's undergraduate research interest training program "Community Resilience Evaluation from the Perspective of Prevention and Control of Public Health Emergencies" (2021838).

\section{References}

1. Lan Yuxin. Community Resilience: A New Proposition of Grassroots Governance System and Ability Modernization [J]. Chinese Non-profit Review,2020,25(01):25-28.

2. Ding Lei, Cai Wei, Ding Jianqing, et al. Considerations on the epidemic situation of novel coronavirus infection [J]. Chinese Science: Life Science,2020(3):247-257.

3. Yan Deru. Building a resilient community emergency management system [J]. Administrative Forum,2020,27(03):89-96.

4. Cui Peng, Li Dezhi, Chen Hongxia, Cui Qingbin. Review and Prospect of Community Toughness Research: Concept, Dimension and Evaluation [J]. Modern Urban Research,2018(11):119-125.

5. Yang Wei. Community Flexibility Assessment from the Perspective of Emergency Management [D]. Dalian University of Technology,2015.

6. Jiang Yuxiao. Study on Tough Community Evaluation System and Optimization Strategies from the Perspective of Waterlogging Prevention [D]. Tianjin University,2018.

7. Fang Dongping, Li Quanwang, Li Nan, Wang Fei, Liu Ying, Gu Donglian, Sun Chujin, Pan Shengjie, Hou Guanjie, Wang Fei, Lu Xinzheng. Community Seismic Safety Toughness Assessment System and Application Demonstration [J]. Engineering Mechanics,2020,37(10):28-44.

8. Holling C S. Holling CS. Resilience and Stability of Ecological Systems. Ann Rev Ecol Syst 4: 1-23[J]. Annual Review of Ecology and Systematics, 1973, 4(1):1-23. 